\title{
VIOLÊNCIA CONTRA PESSOAS IDOSAS PROMOVIDA EM INSTITUIÇÃO DE SAÚDE
}

\author{
Andréa dos Santos Souza', Edméia Campos Meira ${ }^{2}$ \\ e Maria do Rosário de Menezes ${ }^{3}$
}

\begin{abstract}
RESUMO
Pessoas idosas são vítimas reais e em potencial da violência nos serviços de saúde. A pesquisa buscou identificar as concepções de profissionais de saúde sobre a violência contra idosos promovida em seu ambiente de trabalho e as formas mais frequentes de manifestação. Coletaram-se dados entre 14 profissionais de um hospital público do interior da Bahia, por meio de questionário sociodemográfico e entrevista. Coexistem vários modos de compreender a violência relacionados à cultura, às deficiências estruturais e ao comportamento individual. Preconceito contra a pessoa idosa, negligência e discriminação foram frequentemente referidas. Profissionais e idosos têm sido condescendentes com a violência institucional, perpetuada pelo despreparo para atendimento gerontológico e pela desinformação e atitude passiva dos idosos diante dos maus-tratos sofridos.
\end{abstract}

Palavras-chave: Violência. Idoso. Hospitalização. Profissionais de Saúde.

\footnotetext{
${ }^{1}$ Doutoranda do Programa de Pós-Graduação em Enfermagem da Universidade Federal da Bahia e Professora Assistente, Graduação em Enfermagem da Universidade Estadual do Sudoeste da Bahia Jequié/BA, Brasil. andreasouza_75@hotmail.com

${ }^{2}$ Professora Adjunta do Curso de Graduação em Enfermagem da Universidade Estadual do Sudoeste da Bahia,-Jequié/BA, Brasil. edmeiameira@yahoo.com.br

${ }^{3}$ Professora do Programa de Pós-Graduação em Enfermagem da Universidade Federal da Bahia, Brasil. zaramen@bol.com.br
} 


\section{VIOLENCE AGAINST THE ELDERLY IN A HEALTH INSTITUTION}

\section{ABSTRACT}

Elderly people are real and potential victims of violence in health services. The research sought to identify the conceptions of health professionals on the violence against the elderly in their work environment, and the most frequent forms of manifestation. Data were collected from 14 professionals from a public hospital in inland Bahia, through sociodemographic questionnaire and interview. Various ways of understanding violence, related to culture, the structural deficiencies and individual behavior coexist. Prejudice against the elderly, neglect and discrimination were frequently reported. Professionals and the elderly have been lenient with the institutional violence perpetuated by the unpreparedness of gerontology, misinformation and passive attitude of the elderly when faced with mistreatment.

Keywords: Violence. Elderly. Hospitalization. Health Care Professionals.

\section{INTRODUÇÃO}

violência cometida contra pessoas idosas é um fenômeno de amplitude mundial.
Desde a década de 1970, quando se iniciaram as discussões sobre o assunto,
permanece o comportamento de manter silêncio diante do fato. Quando se trata da violência exercida nas instituições há uma carência de estudos que facilitem compreender e intervir de forma a prevenir e combater os maus-tratos aos idosos.

A violência contra idosos perpetrada em hospitais soa ainda mais dissonante com a missão a que estes se propõem, de preservar, proteger a vida, oferecer cuidados de qualidade e garantir os direitos do indivíduo enquanto pessoa e usuário do serviço. 0 enfrentamento é prejudicado pela aceitação da violência institucional como um processo intrínseco aos serviços públicos de saúde, em virtude de sua elevada demanda, escassez de recursos humanos e materiais e inadequação da estrutura física.

0 crescimento da população idosa no Brasil e 0 aumento da procura destas pessoas por serviços de saúde tornam a situação ainda mais preocupante. A participação relativa de idosos no Brasil era de 11,3\% em 2009, e passará para 22,7\% em 2050, segundo estimativa do IBGE (2010). 0 período de velhice também tem se tornado mais longo e chega a extrapolar 30 anos, configurando uma sub-população idosa com necessidades diferenciadas de assistência. Os idosos representam um percentual significativo nas internações hospitalares e sua permanência é mais prolongada em comparação com os demais grupos etários (AMARAL et al., 2004). 
Os estereótipos negativos sobre a velhice, naturalizados na contemporaneidade, influenciam as atitudes dos profissionais e se refletem na qualidade dos cuidados no contexto hospitalar (MARQUES, 2005). Crenças negativas sobre o envelhecimento, como as de que os idosos precisam "descansar", que os investimentos gastos nos cuidados a esta população não têm retorno, que os idosos são decadentes, dependentes, inativos, feios, teimosos e comedidos, são reflexos da visão preconceituosa de uma sociedade cuja cultura está centrada na juventude, na beleza, no corpo jovem e na produtividade. Por outro lado, simultaneamente, observa-se a visibilidade dos idosos por sua longevidade, participação social, dinamicidade, potencial de consumo e independência financeira (MOTTA, 2006).

Associado às questões socioculturais, a falta de uma política de educação permanente em gerontologia, a infraestrutura precária e/ou inadequada nas unidades hospitalares, e a insuficiência de recursos humanos contribuem para o distanciamento entre o cuidado ideal e o real. Seguindo este raciocínio, é possível visualizar que de onde se espera proteção e atenção integral à pessoa idosa por parte dos profissionais e serviços de saúde, poderá haver até mesmo situações de violação de seus direitos. As consequências dos abusos cometidos contra o idoso hospitalizado podem variar desde 0 sofrimento emocional, a ampliação do período de internamento, instalação e piora da incapacidade, agravamento do quadro clínico, desnutrição, desidratação e até mesmo a morte. A falta de poder dificulta que os idosos reajam quando seus direitos são violados.

Segundo a Organização Mundial de Saúde, a violência praticada contra a pessoa idosa é "um ato (único ou repetido) ou omissão que lhe cause sofrimento, angústia e que se reproduz em qualquer relação na qual exista expectativa de confiança" (OMS, 2002). No cotidiano das instituições de saúde, os maus-tratos caracterizam-se pela recusa ou omissão de cuidados necessários aos idosos (negligência), especialmente àqueles com maior grau de dependência.

Acordos assumidos pelo Brasil desde as Assembléias Mundiais sobre 0 Envelhecimento em Viena e em Madri impulsionaram a elaboração de mecanismos de proteção social à pessoa idosa como a Política Nacional do Idoso, o Estatuto do Idoso e a Política Nacional de Saúde da Pessoa Idosa. Ações específicas foram estabelecidas por meio do Plano de Ação para o enfrentamento da violência contra a pessoa idosa (BRASIL, 2005), seguindo as orientações de documento publicado pela Organização Mundial de Saúde e a Rede Internacional de Prevenção de Abusos em Idosos - Inpea (OMS, 2002; INPEA, 2002). Entretanto, os avanços constatados na legislação brasileira não se vêem de modo efetivo na prática.

0 modo como nos relacionamos com as pessoas de diferentes grupos etários é uma construção histórica e sociocultural. Em cada etapa do ciclo vital são estabelecidos direitos e deveres, funções e poderes específicos. Na maioria das culturas observa-se 
aversão à velhice e os idosos ocupam uma posição marginalizada. Deseja-se uma vida longa, mas não ficar velho. A velhice é objeto de uma conotação cruel e injusta de decrepitude, dependência, feiúra e recolhimento. Tais concepções favorecem atitudes discriminatórias.

Pesquisas sobre a violência contra idosos no Brasil apontam para uma cultura negligente que se manifesta nas instituições sociais e de saúde, observada nas relações de despersonalização, de destituição de poder e vontade, bem como na omissão de cuidados específicos (MINAYO, 2003). Em sua tese de doutorado, Berzins (2009) apresentou a interpretação do problema da violência institucional sob a ótica de profissionais de saúde atuantes na emergência de um hospital público. Concluiu que os profissionais não se reconhecem como agentes, transferindo a responsabilidade desta ação para os colegas e para a organização do sistema de trabalho. Em outro estudo, com base em resultados de pesquisa realizada em instituições de saúde da cidade de Salvador-BA, Menezes (2010) constatou que existe uma tendência dos profissionais em estabelecer limites de tempo para viver quando se está doente na velhice, subestimando as capacidades e o desejo que os idosos têm de viver e de por em prática seus projetos de vida.

As hipóteses que tentam explicar as causas da violência contra pessoas idosas nas instituições de saúde são de natureza multifatorial e complexa, guardando estreita relação entre si (MINAYO; SOUZA, 2003). Em primeiro lugar se destacam os fatores macrossociais, tais como a precariedade da assistência às pessoas de todos os grupos etários, a cultura da violência, as representações sociais negativas da velhice, 0 capitalismo, a dominação e os conflitos intergeracionais e o modelo biomédico de cuidado ${ }^{4}$. Em segundo lugar estão imbricadas as condições inadequadas de trabalho nos serviços públicos de saúde, a formação profissional insuficiente e os aspectos subjetivos como comportamento individual, personalidade, sensibilidade para com o sofrimento do outro, questões morais, valores e ética.

Considerando que os trabalhadores da saúde se configuram como um importante recurso na consolidação das políticas públicas específicas às pessoas idosas, este estudo foi delineado com o objetivo de identificar as concepções de profissionais de um hospital público sobre a violência contra idosos e suas formas mais freqüentes de manifestação. A ótica dos trabalhadores sobre a violência institucional oferece um

\footnotetext{
${ }^{4} 0$ modelo biomédico de cuidado está organizado segundo a lógica do paradigma positivista. Neste modelo, o corpo humano é considerado como máquina e a doença, como o mau funcionamento dos mecanismos biológicos, cabendo ao médico intervir e "consertar o mecanismo defeituoso". A influência deste pensamento sobre as práticas de saúde pode ser observada nas ações fragmentadas, na hegemonia do saber médico, na transferência da atenção do doente para a doença, na relação distanciada e despersonalizada entre o profissional e o doente, na supervalorização do uso de medicamentos e de realização de exames diagnósticos (CAPRA, 1982).
} 
vislumbre sobre a sensibilidade para a temática, o modo pelo qual compreendem as suas causas e elaboram possíveis estratégias para prevenir e solucionar o problema.

A instituição em foco dispõe de 200 leitos e serve de referência para aproximadamente 30 municípios do interior da Bahia, Brasil. Para a coleta de dados se adotou um formulário de identificação sociodemográfica e uma entrevista semiestruturada, focalizados nas seguintes questões norteadoras: o que você entende por violência institucional? Na sua concepção, o idoso é violentado em seu ambiente de trabalho? De que forma se manifesta esta violência? A análise se pautou na interação entre os temas emergentes, na articulação destes com o contexto social e cultural local e ainda, nas premissas da Teoria Cultural do Conflito formulada por Ross (1995).

\section{A VIOLÊNCIA SILENCIADA E A VIOLÊNCIA RETRATADA POR PROFISSIONAIS DE SAÚDE DE UMA INSTITUIÇÃO PÚBLICA HOSPITALAR}

Participaram do estudo 14 profissionais de saúde, em sua maioria, adultos jovens, do sexo feminino, assim distribuídos por categoria profissional: 09 profissionais de enfermagem, 02 assistentes sociais, 02 fisioterapeutas e 01 psicólogo. Não houve participação de médicos, pois estes profissionais recusaram colaborar com a pesquisa.

Dos investigados, 50\% admitiram que a violência faz parte do cotidiano na instituição de saúde em que trabalha, e a outra metade negou a sua existência. Este contraste parece ser efeito de diferentes percepções sobre a violência, de graus variados de conhecimento e consciência sobre o fenômeno e da "cultura do silêncio".

Os profissionais participantes da pesquisa (aqui identificados pela letra "P", seguida do número de ordem da entrevista), emitiram diferentes concepções sobre a violência institucional, como exemplificam os seguintes depoimentos:

[...] atos violentos nunca presenciei, mas constrangedores, inúmeros (P1).

[...] de um modo geral, você não respeitar uma dor, um momento de sono, você não respeitar uma fala do paciente, eu acho que é a falta de respeito por si só. Mesmo que não envolva uma agressão física, já é uma violência (P13).

É possível observar que alguns trabalhadores da saúde guardam no imaginário a representação da violência como uma ação que produz sinais corporais visíveis, ameaçadores da vida, como nas circunstâncias de agressões físicas e abusos sexuais. Ação ou omissão cujas consequências são de ordem psicoemocional podem não ser identificadas como violência, ou ainda, podem ser julgadas como de menor valor. 
Dos profissionais que reconheceram a existência da violência perpetrada na instituição de saúde em que trabalham, três relataram que é possível observá-la com freqüência: "[...] rotineiramente a gente vê" (P2). Nota-se que habitualmente a violência aparece, correndo-se o risco dela perder a estranheza para os atores que compõem este cenário. Sobre esta questão, Cruz Neto e Moreira (1999, p.34) escrevem: "Exatamente por ser exercitada nas ações diárias de instituições consagradas por sua tradição e poder, esta forma de violência costuma ser considerada como algo natural que, na maioria das vezes, não é contestada".

Embora esta prática apareça de forma usual, os profissionais não se reconhecem como agentes da violência. Trata-se de um problema "produzido pelo outro". Os maustratos são atribuídos então a acompanhantes, colegas de profissão e a outros da equipe multidisciplinar de saúde, como observado nos relatos a seguir: "A gente vê até de acompanhante... (P4). [...] porque às vezes os médicos não têm assim, aquela visão mais detalhada. E aí, muitas vezes problemas que deveriam ser mais aprofundados, não são" (P5).

Este fato é perfeitamente compreensível, pois teriam que admitir que cometem um crime previsto nas legislações de proteção à pessoa idosa. Por isso, não se identificam enquanto agressores e combatem de modo intencional, ou não, esta idéia. Quando não se tem consciência da prática abusiva cometida contra pessoas idosas, ou esta é negada, profissionais criam uma expectativa de mudança exterior a si mesmos.

\section{A VIOLÊNCIA INSTITUCIONAL COMO UMA QUESTÃO CULTURAL}

A violência institucional também foi analisada pelos profissionais investigados como uma conduta cultural, cujas relações de desvalorização aprendidas na convivência com idosos da família e comunidade são reproduzidas na instituição:

[...] a gente sabe que é uma questão cultural, infelizmente nosso país, está no ocidente, ele não foi preparado. Não é como o oriente, que tem todo um olhar de valorização do idoso. Então por uma questão cultural, as pessoas não valorizam esse idoso, não observa ele como uma fonte de riqueza de conhecimento (...) (P11).

$\mathrm{Na}$ atualidade, a velhice continua associada, sobretudo, a doenças e debilidade física. No Brasil, a população adulta faz uma avaliação desta fase da vida mais negativa que a dos próprios idosos. No imaginário social os aspectos ruins da velhice são: a debilidade física e as enfermidades, a dependência física e a discriminação social, cuja percepção é de que esta última possa ter se agravado mais recentemente. As coisas boas da velhice estão relacionadas à experiência de vida, à sabedoria, ao tempo livre, à 
independência econômica, aos direitos sociais e à proteção familiar (VENTURINI, BOKANY, 2007).

A partir de suas observações em diferentes sociedades, Ross (1995) percebeu diferenças na prática da violência. Seus achados foram sistematizados e explicados por meio de um modelo que denominou a cultura do conflito. Para este autor, os comportamentos conflitivos geralmente estão ancorados nas primeiras relações sociais da infância e podem ainda ser reforçados por práticas e instituiç̧ões sociais.

A observação do tratamento recebido pelos idosos na família, na comunidade e nos meios de comunicação que veiculam sua imagem, influencia a conduta ao longo da vida. A reprodução destas ações as torna tão naturalizadas e aceitas no contexto sociocultural que muitas vezes são implícitas para o sujeito, ou seja, indisponíveis na experiência consciente.

A violência institucional não é menos brutal que a violência física e de igual modo constitui uma violação dos Direitos Humanos, pois deflagra sentimentos de culpa, solidão, dependência, inutilidade e aumenta a sensação de desamparo. A negligência, sua manifestação mais notória, infringe os direitos humanos básicos, como o da vida, da integridade pessoal, da dignidade e impede o idoso de gozar do mais alto padrão de saúde possível. Esta concepção pode ser observada também nos seguintes depoimentos: "[...] é um direito dele [referindo-se ao idoso], como de todo cidadão, ser assistido, ser acompanhado por uma equipe multiprofissional" (P9); "Considero a violência como um problema que afeta a dignidade e respeito, a dignidade deles [dos idosos]" (P1).

Diante do preconceito e exclusão social a que os idosos têm sido submetidos na família, na sociedade e nas instituições públicas, há um movimento internacional para sensibilizar, promover e garantir que os mesmos tenham, como qualquer outro cidadão, seus direitos resguardados desde a infância até a velhice. Este não deixa de ser um alerta aos governos mundiais que introduzam em seus programas os "Princípios das Nações Unidas a favor das pessoas idosas" de independência, participação, dignidade, cuidados e auto-realização (0NU, 1991). Trata-se de uma mudança de paradigma na elaboração de Políticas Públicas para a população idosa. A centralidade das políticas se desloca do idoso como uma pessoa de necessidades para o idoso como titular de direitos (civis, políticos, econômicos, sociais e culturais). Portanto, o Estado e a sociedade deverão provê-los (CEPAL, 2009).

No contexto investigado, a violência institucional contra a pessoa idosa se apresenta de múltiplas formas e se perpetua amparada no despreparo gerontológico dos profissionais sobre as questões de saúde deste grupo populacional, na desinformação e na atitude passiva dos idosos diante dos maus-tratos sofridos. 


\section{A VIOLÊNCIA INSTITUCIONAL COMO UM PROBLEMA ESTRUTURAL}

A violência institucional foi também apresentada como consequiência da deficiência na atenção primária, comprometendo a saúde dos idosos em virtude especialmente da descompensação de doenças crônicas que poderiam ser prevenidas. Uma enfermeira declarou: "[...] quando eu vejo o paciente chegando no pronto socorro de um problema que a gente vê que é primário, que poderia ser tratado e quando ele vem geralmente pra gente, ele já vem grave" (P7).

A culpabilização individual de pessoas integrantes do mesmo contexto ou de níveis de atenção de menor complexidade disfarça a causalidade complexa da violência institucional e de sua estreita relação com graves problemas estruturais. É necessária uma reflexão mais aprofundada sobre os processos que sustentam 0 atendimento à saúde da população idosa nos serviços hospitalares, na contemporaneidade, afinal: "todo ato humano está inserido em um contexto social, histórico e territorial (PEDRAZZINI, 2006, p. 79).

Cumpre ressaltar que a longo de sua trajetória de vida, a maioria dos atuais idosos passou por privações que os levaram a uma exclusão social de que amargam as consequiências, agravadas na velhice. Dados publicados pelo IBGE (2010) sobre o perfil dos idosos brasileiros mostram que idosos de cor branca $(55,4 \%)$ é a maioria em relação à parda $(36,1 \%)$ e à preta $(7,2 \%)$. No que diz respeito ao processo educativo formal, $50,2 \%$ têm menos de quatro anos de estudo, 43,2\% dos idosos recebem até um salário mínimo e apenas 29,7\% dos idosos brasileiros têm plano de saúde.

Problemas estruturais profundos como a pobreza, o analfabetismo e a desigualdade social não atingem apenas a população idosa brasileira. Todavia, pessoas pertencentes a este grupo são vítimas reais e em potencial da violência nos serviços de saúde em virtude de agregar as alterações do envelhecimento, possibilidade de sofrer de múltiplas doenças crônicas, e ser objeto de estereótipos negativos da velhice. Além disso, seu estado de saúde se deteriora rapidamente quando há demora no atendimento ou não são consideradas no plano terapêutico as especificidades da pessoa que envelhece.

Ao relacionar as explicações para a origem de conflitos proposta por Ross (1995) e a violência contra idosos promovida na instituição hospitalar, observa-se que a origem do conflito é resultante da interação de múltiplos fatores. 0 comportamento dos envolvidos geralmente não evolui para agressão física. Neste cenário predominam a negligência, a omissão e a discriminação. 0 idoso fica exposto a um estresse físico e mental, por ter suas expectativas frustradas quanto à assistência e ao alívio de sofrimento; enquanto que o profissional age compreendendo-se como correto diante das condições inadequadas de trabalho que the são oferecidas. Nestas circunstâncias, o conflito é incitado pela elevada demanda de trabalho, falta de infraestrutura, problemas pessoais e desgaste pela dupla jornada de trabalho. A remuneração dos trabalhadores do 
serviço público de saúde é baixa, obrigando-os a terem mais de um vínculo empregatício para sua sobrevivência.

0 tempo disponível para atendimento de cada idoso fica reduzido e as prioridades estabelecidas nestes "encontros" são de cunho biológico, das rotinas previstas na dinâmica do trabalho hospitalar e condizente com o modelo assistencial predominante. Este depoimento reforça essa afirmação: "A gente faz aqui um tratamento que tenta humanizar, mas ao mesmo tempo eu sinto que você não oferece uma assistência completa porque não tem tempo" (P2). Pesquisas realizadas com profissionais de enfermagem em instituições hospitalares de Portugal também apontaram resultados semelhantes aos encontrados nos discursos de profissionais deste estudo quanto à falta de tempo para cuidar adequadamente dos idosos (CARDOSO, 2000; CARVALHAIS \& SOUSA, 2011).

Hospitais de referência localizados no interior do estado costumam receber grande demanda de pacientes provenientes de áreas rurais dos municípios circunvizinhos. 0 deslocamento do local de origem até o serviço de saúde é longo e nem sempre ocorre em transporte apropriado. Quando chegam acompanhados de seus familiares, os idosos encontram uma superlotação e esperam horas e até mesmo dias por uma vaga de internamento em condições que ferem a sua dignidade: "Muitas vezes tem pessoas idosas que ficam dias no pronto socorro. Mas eu não posso colocar aí,... não é como um descaso. Está lá é por falta mesmo de vaga, porque quando existe a vaga, aí existe a prioridade" ( $\mathrm{P} 5$ ). Vale lembrar que a espera prolongada pode resultar na morte do idoso, pois a piora do quadro de saúde se desenvolve muito rapidamente pela redução da reserva funcional. Quando necessitam de internamento e não há vagas disponíveis nas enfermarias, os idosos permanecem em macas estreitas, sem colchões e sem grades que lhes ofereçam segurança contra quedas. 0 direito à privacidade também é violado e o seu corpo, exposto.

Em sociedades capitalistas, a imagem do corpo envelhecido é como o de uma árvore infrutífera que é necessário extirpar. Para as idosas, a situação é ainda pior, pois são mais cobradas socialmente em relação à beleza e jovialidade (MOTTA, 2002). Quando não conseguem mais disfarçar as marcas impressas no corpo pelo tempo vivido, mediante o uso dos vários recursos da indústria cosmética, é comum ouvi-las dizer que 0 corpo tem uma idade e a mente tem outra, superior.

$\mathrm{Na}(\mathrm{s})$ circunstância(s) em que o corpo, além de envelhecido está alterado por enfermidades, a imagem social fica ainda mais distorcida e negativa. Duplamente decadente, incompetente e inútil, em primeiro lugar pela velhice e, em segundo, pela doença. Destituídos de valor, os corpos dos idosos ficam à mostra, pois não incitam a sensualidade, são visualizados como degradados e cujo caminho é a finitude. Esta concepção desconsidera a dignidade humana e a singularidade da pessoa idosa com sua 
história de vida, enquanto membro de uma família e de uma sociedade. Para uma maior valorização do idoso é necessário integrar o território biológico do seu corpo ao simbólico, pois só assim será possível visualizar o corpo envelhecido como o mais belo traço da memória da vida. Enxergá-lo em sua subjetividade e como fonte inesgotável de descobertas (SANT'ANNA, 2001).

Para alguns profissionais, cuja sensibilidade se mostra mais aguçada para as questões gerontológicas, a exposição pública dos idosos é um quadro que causa consternação:

0 que me angustia é essa questão do corredor, de ficar exposto. Às vezes ele [referindo-se ao idoso] está ali de fralda, de sonda, sem roupa, ele está com uma ferida no pé com odor fétido e todo mundo rejeita. É um mau-trato. Ninguém chega perto por causa daquele odor. Isso eu já vi, é constrangedor (P12).

Esta situação reforça a idéia de que existem doenças, ou problemas de saúde que causam maior estigma que outros. Uma ferida com necrose, sem dúvida, afeta a autoimagem, a auto-estima e contribui para o isolamento social. Neste caso, desenvolve-se uma desintegração da imagem que o idoso faz de si, como consequiência de experiências negativas. Os sofrimentos físicos e psicossociais se instalam gerando um sentimento de peso pelo comprometimento da autonomia (CANESQUI, 2007). Os profissionais de saúde devem estar atentos para prevenir ou intervir em tais situações, não apenas no âmbito biológico (tratamento da ferida), mas nas consequências psicoemocionais que estas podem causar.

Em geral, o corpo no hospital é visível por sua dimensão biológica. Conhecimentos da anatomia e fisiologia norteiam o exame minucioso de cada parte do corpo, em busca de sinais capazes de desvendar o que está produzindo sofrimento. Um arsenal de equipamentos é utilizado para rastrear o corpo enfermo a fim de oferecer informações mais detalhadas sobre a doença. Sangue, fezes, urina, escarro, secreções de ferimentos, tudo é minuciosamente investigado. 0 paciente perde a sua identidade, 0 poder sobre o seu corpo e passa a ser codificado de acordo com a sua doença e o leito em que está internado. A higiene corporal, a alimentação, o repouso, as visitas seguem um horário rígido, orientado pelas normas institucionais e interesses profissionais. 0 mundo do hospital desrespeita o direito à privacidade, às relações sociais, à condição de sujeito. Fixa o corpo num espaço para ser cuidado e vigiado (AZEVED0, RAMOS, 2006).

Quando as condições físicas e estruturais são desfavoráveis, tudo mais se agrava. Aumenta a vulnerabilidade do idoso à exposição de seu corpo a situações vexatórias, como pode ser observado neste depoimento de um dos profissionais investigados: 
(...) eu considero constrangedor a gente vê num corredor de emergência, um paciente todo evacuado e não ter uma privacidade pra gente realizar essa higiene nele. A gente precisa fazer aquele biombo humano, juntar 2, 3 pessoas, pra tentar uma forma de realizar aquela higiene no meio de um corredor (P1).

Foi também relatado o preconceito em relação à dor referida pelo idoso, como uma manifestação da violência institucional, pois se acredita que esta é uma queixa própria da velhice: “(...) é complicado dizer [referindo-se a violência institucional]... Mas, tipo assim, seria mesmo o preconceito, porque às vezes a gente negligência uma dor. Fala assim: veio pra cá por causa de uma dor? 0 idoso sente dor mesmo? Mas, a gente não está pra pesar e nem dosar a dor de ninguém" (P1). A desqualificação gerontológica e 0 preconceito comprometem a qualidade da assistência ao idoso hospitalizado que sofre uma experiência dolorosa. A dor é frequente neste grupo populacional em virtude de desordens crônicas, artrites, osteoporose, por isso, para muitos, está associada à chegada da velhice. A crença de que idosos perdem a percepção dolorosa impede que os profissionais atuem prontamente quando se queixam. As conseqüências da dor para o idoso são múltiplas: limita a mobilidade, causa medo, ansiedade, impede a conservação da integridade, provoca estresse, favorece o isolamento social, dentre outras (CELICH, GÁLON, 2009).

Numa perspectiva biológica, a literatura científica admite haver alterações neuroanatômicas e neuroquímicas na transmissão ao longo das fibras nervosas A-delta e C, mas não está claro que possa alterar a experiência individual. Do ponto de vista antropológico, os humanos diferem no seu modo de reagir às experiências dolorosas, mesmo que a doença seja a mesma. Pode ainda o mesmo homem reagir de modo diverso de acordo com as circunstâncias. As manifestações da dor variam de acordo com aspectos sociais, culturais, pessoais e contextuais (LE BRETON, 1999).

A compreensão da experiência subjetiva da dor e a escuta sensível constituem um processo fundamental para uma assistência adequada aos idosos com queixas álgicas. A administração de medicamentos não é a única opção terapêutica. A adoção de medidas não farmacológicas como massagens, acupuntura, termoterapia, cinesioterapia, estimulação elétrica, terapia cognitivo-comportamental produzem resultados satisfatórios (TOYOSHIMA, 2007). Sobretudo é importante que o profissional dispense tempo, transmita segurança e proteção ao idoso.

\section{A VIOLÊNCIA INSTITUCIONAL COMO UMA QUESTÃO INDIVIDUAL}

Características individuais foram também consideradas na origem da violência institucional contra a pessoa idosa. 0 perfil do provável agressor é de um profissional 
impaciente, com pouca capacidade empática, como está exemplificado na seguinte fala de um dos colaboradores do estudo:

Ele, [o idoso], é muito lento nas suas ações. Então eu quero que ele vá pra o banheiro, eu fico puxando, falando, vá logo e usando palavras que machucam, de baixo calão: "vumbora velho, bora, bota esse pé no chão", que eu já vi muita gente falando isso. "Anda logo! Ah! véio só presta pra empatar"... Ele [0 idoso] ali quietinho. Porque eles parecem uns bichinhos. Assim, tudo que a gente fala pra o idoso, ele toma como lei. Aí ele fica ali quietinho, não lhe responde nada, só arrastando o pezinho (P10).

Com base neste depoimento, uma das explicações para a violência institucional está centrada na conduta individual dos profissionais. A observação de que em circunstâncias iguais os profissionais reagem diferentemente, sugere a participação de um componente particular, subjetivo. Ross (1995), referindo-se à cultura do conflito expõe que o comportamento humano é moldado pelas relações estabelecidas na infância e pela estrutura da sociedade na qual se vive. Partindo destas premissas, o autor explica o comportamento conflitivo (violento) fundamentado em duas teorias: a psicocultural e a socioestrutural, sendo que cada uma delas percebe de modo diferenciado a causa básica dos conflitos e sugere uma abordagem peculiar de intervenção para sua resolução.

Na primeira delas, a Teoria Psicocultural, o autor descreve que o modo de se relacionar com as pessoas é aprendido e compartilhado na infância para depois ser reproduzido na vida adulta. Nesta perspectiva o agressor é considerado uma vítima do processo de socialização. Este modelo de conduta social foi designado por Ross de "disposições psicoculturais", a partir das quais o grupo ou o indivíduo processam os acontecimentos. Este enfoque é útil para compreender os motivos pelos quais um comportamento considerado agressivo pode ser interpretado como natural pelos envolvidos na situação. Os seres diferentes experimentam vivências distintas que condicionam interpretações únicas.

Por sua vez, na segunda teoria, denominada de Socioestrutural, Ross expõe que a sociedade é que determina a probabilidade de quem vai ser o agressor e 0 agredido. Como dito anteriormente, nas sociedades ocidentais, o idoso tem pouco valor e está destituído de poder. 0 próprio idoso assimila os estereótipos de fraco, inútil e dependente. Por isso, assume uma postura passiva, de suportar os maus-tratos sem falar. Nesta circunstância 0 silêncio conspira contra 0 idoso e contribui para perpetuar a violência institucional. 
Assim como a profissional expôs o perfil do agressor, apontou também características desejáveis às cuidadoras de idosos: uma pessoa paciente, que goste de idosos e que projete a sua imagem ou a de seus pais no idoso hospitalizado:

(...) Pra você trabalhar com o idoso você tem que gostar. Você tem que se por no lugar dele, você tem que colocá-lo como alguém da sua família. Como você gostaria que tivessem tratando o seu pai, a sua mãe? Eu sempre coloco assim, que poderia ter sido a minha mãe, ou o meu pai (P10).

No estudo realizado por Leite e Gonçalves (2009) com 74 profissionais de enfermagem de 14 hospitais do Rio Grande do Sul, as autoras encontraram resultados semelhantes ao perfil descrito pela profissional do hospital baiano. A partir dos depoimentos colhidos admitiram que há necessidade destes profissionais terem qualidades pessoais de vocação ou disposição para o cuidado de idosos. Contudo, não consideraram que estas fossem suficientes para o real atendimento integral dos pacientes, carecendo de conhecimentos e habilidades especializadas gerontogeriátricas.

Dada a naturalidade com que é visualizada a violência institucional, por parte dos profissionais que admitiram ter presenciado maus-tratos contra a pessoa idosa, somente uma referiu ter se posicionado: “(...) já vi e intervi..., de tomar a assistência dele [referindo-se ao colega]. Pode deixar que eu faço, não precisa você cuidar, pode deixar que eu cuido"(P10). Pouca visibilidade tem sido dada ao modo como os idosos hospitalizados estão sendo cuidados e a partir dos resultados deste estudo, admite-se que a maioria dos profissionais e dos idosos têm sido condescendentes com a violência institucional. Vive-se neste âmbito o paradoxo de uma violência sem eco.

\section{CONSIDERAÇÕES FINAIS}

A violência institucional em serviços de saúde é um grave problema de origem multifatorial e amplitude mundial. No entanto, é nos países em desenvolvimento como o Brasil que se faz sentir quão distante se está em garantir àqueles de mais idade os direitos fundamentais à vida, à integridade e à saúde, como a qualquer outro cidadão. A maioria dos idosos brasileiros sobrevive em precárias condições e com problemas de saúde, para os quais buscam assistência exclusiva no Sistema Único de Saúde. É frustrante e contraditório ser violentado onde se espera encontrar proteção, segurança e atendimento resolutivo.

A violência permanece silenciada, por isso o retrato que se tem é mal revelado. Os profissionais investigados que atenderam à solicitação de quebrar o silêncio expressaram vários modos de compreender a violência: uma prática habitual produzida pelo outro; 
uma conduta cultural, uma consequência da deficiência estrutural e um comportamento individual.

As manifestações mencionadas de violência contra a pessoa idosa hospitalizada foram: negligência, preconceito, discriminação, insuficiência de leitos, permanência insalubre em corredores, desassistência, negação do direito à privacidade e a ser ouvido, pressa e rispidez no atendimento dispensado pelos profissionais.

Tendo em vista que os profissionais não se reconhecem como perpetradores da violência, esperam por mudanças exteriores a si mesmos. Por isso, é tão necessário que este problema seja discutido em cada instituição de saúde e assim promover uma reflexão sobre o que cada um pode fazer para mudar esta triste realidade. Um bom começo é esclarecer sobre a violência institucional, estimular uma visão mais positiva da velhice e implantar a cultura de solidariedade intergeracional.

Há que se ampliar os recursos destinados à saúde para investimentos na capacitação de profissionais, criação de uma Rede de Atenção à Saúde da Pessoa Idosa, fortalecimento da atenção primária, ampliação dos recursos humanos e melhorias na infra-estrutura dos hospitais. É necessário, ainda, vontade política e exercício da cidadania para que se tornem efetivas as Políticas públicas e sejam assegurados os direitos humanos universais. Melhores condições de vida na infância, juventude e fase adulta serão capazes de naturalmente produzir uma velhice mais digna. 0 desafio está lançado. Agora é preciso avançar, pois à medida que o tempo passa as mudanças se tronarão cada vez mais urgentes.

\section{REFERÊNCIAS}

AMARAL, Ana Cláudia Santos; COELI, Cláudia Medina; COSTA, Maria do Carmo Esteves da; CARDOSO, Vânia da Silva; TOLEDO, Ana Lúcia Araújo de; FERNANDES, Carla Rodrigues. Perfil de morbidade e de mortalidade de pacientes idosos hospitalizados. Cad. Saúde Pública, v.20, n.6, p. 1617-26, nov-dez, 2004.

AZEVED0, Rosimeyre Capriata de Souza; RAMOS, Flávia Regina Souza. Modos de conhecer e intervir: a constituição do corpo no cuidado de enfermagem no hospital. Texto Contexto Enfermagem. Florianópolis, v. 15(Esp.), p. 55-63, 2006.

BERZINS, Maria Anselma Viana da Silva. Violência institucional contra a pessoa idosa: a contradição de quem cuida. Tese doutorado. São Paulo: Faculdade de Saúde Pública USP, 2009.

BRASIL. Presidência da República. Subsecretaria de Direitos Humanos. Plano de Ação para o enfrentamento da violência contra a pessoa idosa. Brasília, 2005. 
CANESQUI, Ana Maria (org). Olhares socioantropológicos sobre os adoecidos crônicos. São Paulo: Editora Hucitec, 2007.

CARDOSO, Maria Augusta Grou Moita. Cuidar em Gerontologia. Uma análise etnográfica da prática dos enfermeiros. Dissertação de Mestrado. Universidade do Porto: Instituto de Ciências Biomédicas Abel Salazar, 2000.

CARVALHAIS, Maribel Domingues; SOUSA, Liliana. Promover a qualidade de cuidados de enfermagem a pessoas idosas hospitalizadas. Revista de Enfermagem Referências. III Série, n.3, p.75-84, março, 2011.

CELICH, Kátia Lilian Sedrez; GÁLON, Cátia. Dor crônica em idosos e sua influência nas atividades da vida diária e convivência social. Rev. Bras. Geriatr. Gerontol.,v.12, n.3, p. 345-359, 2009.

CEPAL (Comissão Económica para América Latina e Caribe) / ONU (Organização das Nações Unidas). Envejecimiento, derechos humanos y políticas públicas. Editora Sandra Huenchuan. Santiago de Chile, 2009.

CRUZ NETO, Otávio; MOREIRA, Marcelo Rasga. A concretização de políticas públicas em direção à prevenção da violência estrutural. Ciência \& Saúde Coletiva, v.4, n.1, p.33-52, 1999 .

INPEA. REDE INTERNACIONAL DE PREVENÇÃO DE ABUSO EM PESSOAS IDOSAS. Missing Voices: views o folder persons on Elder abuse. Genebra: WHO/INPEA, 2002 INSTITUTO BRASILEIRO DE GEOGRAFIA E ESTATÍSTICA. Sintese de indicadores Sociais. Uma análise das condições de vida da população brasileira. Estudos e Pesquisas, Informação demográfica e socioeconômica, $n^{0}$ 27. Rio de Janeiro: IBGE, 2010.

LE BRETON, David. Antropología del dolor. Editorial Seix Barral, 1999.

LEITE, Marinês Tambara; GONÇALVES, Lúcia Hisako Takase. A enfermagem construindo significados a partir de sua interação social com idosos hospitalizados. Texto Contexto Enfermagem. Florianópolis, v.18, n.1, p. 108-115, jan.-mar., 2009.

MARQUES, Isaura. Atitudes dos enfermeiros face aos idosos. Interações [on-line]. Escola Superior de Altos Estudos: n. 8, p. 209-222, 2005.

MENEZES, Maria do Rosário de. Violência contra Idosos: é preciso se importar! In:BERZINS, Maria Anselma Viana da Silva; MALAGUTTI, William (orgs). Rompendo o silêncio: faces da violência na velhice. São Paulo: Martinari, 2010.

MINAYO, Maria Cecília de Sousa. Violência contra idosos: relevância para um velho problema. Cad. Saúde Pública, Rio de Janeiro, v.19, n.3, p.783-791, mai.-jun., 2003.

MINAYO, Maria Cecília de Sousa; SOUZA, Edinilsa Ramos de. As múltiplas mensagens da violência contra idosos. In: . Violência sobre o olhar da saúde: a infra- 
política da contemporaneidade brasileira. Rio de Janeiro: Editora Fiocruz, p. 223-242, 2003.

MOTTA, Alda Britto da. Envelhecimento e sentimento do corpo. In: MINAYO, Maria Cecília de Sousa; COIMBRA JÚNIOR, Carlos Everaldo Alvares. Antropologia, Saúde e Envelhecimento. Rio de Janeiro: Editora FIOCRUZ, 2002, p. 37-50.

. Visão Antropológica do Envelhecimento. In: FREITAS, Elizabete Viana de. et al. Tratado de Geriatria e Gerontologia. Rio de Janeiro: Guanabara Koogan, p. 78-82, 2006.

ORGANIZAÇÃO DAS NAÇÕES UNIDAS. Princípios da Organização das Nações Unidas a favor das pessoas idosas. 1991. Disponível em

$:<$ http://www.bioetica.ufrgs.br/onuido.htm>. Acesso em: 03.07.2012.

ORGANIZAÇÃO MUNDIAL DE SAÚDE. World Report on Violence and Health. Genebra: WHO, 2002.

PEDRAZZINI, Yves. Relações da violência. In: . A violência das cidades.

Petrópolis: Vozes, 2006, p.139-177.

ROSS, Marc Howard. La Cultura del Conflicto. Las diferencias interculturales en la práctica de la violencia. Buenos Aires: Ediciones Paidós Ibérica, 1995.

SANT’ANNA, Denise Bernvzzi de. É possível realizar uma História do corpo? In: SOARES, Carmem Lúcia (org). Corpo e História. Campinas: Autores Associados, p. 3-23, 2001.

VENTURINI, Gustavo; BOKANY, Vilma. A velhice no Brasil: contrastes entre o vivido e 0 imaginado. In: NERI, Anita Liberalesso. Idosos no Brasil: vivências, desafios e expectativas na terceira idade. São Paulo: Editora Fundação Perseu Abramo, Edições SESC, p.21-31, 2007.

TOYOSHIMA, Marcos Tadashi Kakitani. Dor. In: CAVALCANTI, Euclides Furtado de Albuquerque; MARTINS, Herlon Saraiva (editores). Clínica Médica: dos sinais e sintomas ao diagnóstico e tratamento. Barueri, SP: Manole, Cap.7, p. 55-67, 2007.

\section{AGRADECIMENTOS}

Aos graduandos em Enfermagem e bolsistas de Iniciação Científica: Camila Calhau Andrade e Arivaldo Pereira dos Reis Júnior, pela participação na coleta de dados. 